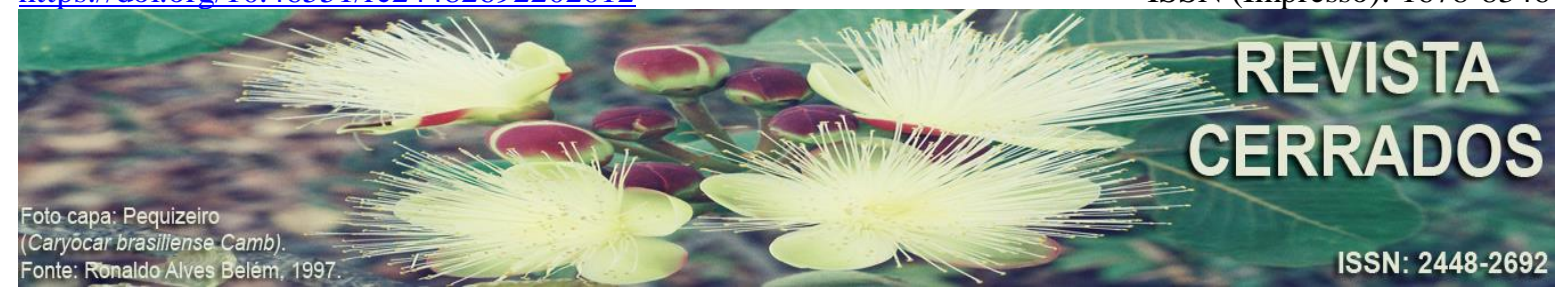

\title{
O PERFIL DOS SUJEITOS SOCIAIS QUE COMPÕEM AS REDES DE RECICLAGEM DO ESTADO NO RIO DE JANEIRO ${ }^{1}$
}

\section{THE PROFILE OF THE SOCIAL SUBJECTS THAT COMPOSE THE RECYCLING NETWORKS IN THE STATE OF RIO DE JANEIRO}

\section{EL PERFIL DE LOS SUJETOS SOCIALES QUE INTEGRAN LAS REDES DE RECICLAGE EN EL ESTADO DE RIO DE JANEIRO}

\author{
Uilmer Rodrigues Xavier da Cruz \\ Universidade Federal de Minas Gerais - UFMG, Belo Horizonte, Minas Gerais, Brasil \\ E-mail: <uilmer@ufmg.br>.
}

\begin{abstract}
RESUMO
A construção da identidade é fruto das relações entre os indivíduos e os espaços, compondo uma dinâmica que está em contínua construção. Dessa forma, os sujeitos sociais possuem características que resultam de suas relações com os espaços e da soma das escalas imbricadas e estabelecidas em seus múltiplos relacionamentos e de diversas maneiras. Diante disso, demarca-se o propósito deste artigo: promover uma compreensão geográfica acerca de sujeitos sociais e redes e, mais especificamente, de sujeitos relacionados à Rede de Reciclagem do Estado do Rio de Janeiro (RRERJ) sobre os modos pelos quais compõem suas relações. Assim, o objetivo, aqui, é compreender as relações de poder que existem nas atividades de reciclagem e catação, observando o espaço e a construção da identidade dos sujeitos que compõem a RRERJ e lhes traçando um perfil mais detalhado. Nesse seguimento, é possível inferir que a discussão deste artigo pode levar a uma análise das relações de trabalho e da exploração dos sujeitos que trabalham na reciclagem de resíduos recicláveis, fomentando uma melhor compreensão da organização desigual do espaço.
\end{abstract}

Palavras-chave: Perfil de catadores. Produção de identidades. Catação e relações de poder.

\begin{abstract}
The construction of identity is the result of the relationships between people and spaces, comprising a dynamic in continuous construction. Thus, social subjects have characteristics

\footnotetext{
${ }^{1}$ Este artigo compõe a pesquisa As redes de produção da reciclagem no estado do Rio de Janeiro: circuitos espaciais e desafios dos catadores de materiais recicláveis, desenvolvida na linha de pesquisa de Geografia e Relações de Poder do curso de Mestrado em Geografia do Programa de Pós-Graduação em Geografia da Universidade do Estado do Rio de Janeiro.
}

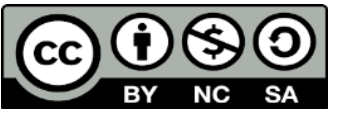

Revista Cerrados, Programa de Pós-Graduação em Geografia, Departamento de Geociências (UNIMONTES 
CRUZ, U. R. X. C.

O perfil dos sujeitos sociais que compõem as redes de reciclagem do estado do Rio de Janeiro

resulting from their relationships with spaces and the sum of the overlapped and established scales in their multiple relationships and in different ways. Therefore, this study aimed to promote a geographical understanding of social subjects and networks, more specifically, the subjects related to the Recycling Network of Rio de Janeiro (RRERJ), Brazil, regarding the ways they develop their relationships. Thus, the purpose of this research is to understand the power relationships in waste recycling and collection activities, observing the space and the construction of the subjects' identity who compose the RRERJ, establishing a more detailed profile of these people. In this sense, it is possible to infer that the discussion in this paper can lead to an analysis of working relationships and exploitation of subjects who work in the recycling of recyclable waste, promoting a better understanding of the unequal organization of space.

Keywords: Waste pickers' profile. Production of identities. Picking and power relationships.

\section{RESUMEN}

La construcción de identidad es el resultado de las relaciones entre individuos y espacios, componiendo una dinámica que está en construcción continua. Por lo tanto, los sujetos sociales tienen características que resultan de sus relaciones con los espacios y de la suma de las escalas superpuestas y establecidas en sus relaciones múltiples y de diferentes maneras. Así, este estudio tuvo como objetivo promover una comprensión geográfica acerca de los sujetos sociales y de las redes, más específicamente, de los sujetos relacionados con la Red de Reciclaje de Río de Janeiro (RRERJ), Brasil, en cuanto a las formas en que desarrollan sus relaciones. Por lo tanto, se propuso comprender las relaciones de poder que existen en las actividades de reciclaje y recolección de desechos, observando el espacio y la construcción de la identidad de los sujetos que componen la RRERJ y estableciendo un perfil más detallado de estas personas. En este sentido, es posible inferir que la discusión de este artículo puede conducir a un análisis de las relaciones de trabajo y explotación de los sujetos que trabajan en el reciclaje de residuos reciclables, promoviendo una mejor comprensión de la organización desigual del espacio.

Palabras clave: Perfil de los recolectores. Producción de identidades. Recolección y relaciones de poder.

\section{INTRODUÇÃO}

Conceitualmente, é possível estabelecer uma compreensão acerca do espaço geográfico enquanto um construto social. Como afirma Massey (2008), o espaço se constitui a partir de uma tríade que é interdependente em seus pontos. Desse modo, ele é produto das inter-relações que se estabelecem socialmente, por meio dos sujeitos, é esfera das multiplicidades que compõem as relações sociais de maneira identitária e está em constante construção, sendo, portanto, dinâmico, mantendo-se em um contínuo devir. 
CRUZ, U. R. X. C.

O perfil dos sujeitos sociais que compõem as redes de reciclagem do estado do Rio de Janeiro

Nessa mesma linha de raciocínio, é importante destacar que, sem as relações sociais, o espaço não se constitui pré-discursivamente e, concomitantemente, as relações não se estabelecem sem a existência do espaço (CORRÊA, 2000). Essa compreensão corresponde ao entendimento de que o espaço e as relações sociais são coconstituintes, isto é, que eles se estabelecem a partir de uma interdependência. Isso significa que os sujeitos sociais têm em suas trajetórias cotidianas nuances resultantes de espacialidades específicas, assim como da soma de múltiplas escalas intrínsecas às relações estabelecidas das mais diferentes formas.

É nesse seguimento que se demarca o propósito desta reflexão: uma compreensão geográfica acerca de sujeitos sociais e redes (conceito-chave da disciplina científica em questão) e, mais especificamente, de sujeitos relacionados à Rede de Reciclagem do Estado do Rio de Janeiro (RRERJ) sobre os modos pelos quais compõem suas relações.

Assim sendo, não se pode deixar de lembrar que é o próprio sistema capitalista de produção que demanda que existam sujeitos sociais que estejam envolvidos na prática da catação e da reciclagem. Tais sujeitos representam a força de trabalho de uma população explorada e marginalizada que sofre com os baixos rendimentos, enquanto aquele que a explora lucra com o fruto dessa força. O trabalho desses sujeitos sociais, catadores de materiais recicláveis, é o elo mais frágil na base da hierarquia, mesmo com toda sua importância social, e ele está intimamente ligado à luta pela sobrevivência, uma vez que a pouca qualificação e a ausência de outras alternativas de trabalho formal fazem com que o acesso dessa população a determinadas esferas sociais seja limitado.

Em vista disso, a discussão deste artigo se divide em três partes. A primeira, Catação e relações de poder, procura refletir como a prática da coleta seletiva - e toda sua rede desigual - é retroalimentada pela lógica do sistema capitalista, favorecendo sempre apenas uma parcela da sociedade. Além disso, contempla a reciclagem enquanto rede de produção, e não apenas de relações sociais, a qual é composta por diversos atores que exercem funções diferenciadas na produção dos materiais reciclados. Por mais que o poder parta de diferentes pontos da rede e de diferentes atores, há circulação desigual de capital, informação e poder entre seus participantes, sendo estes ordenados hierarquicamente, mediante a posição social em que se situam.

A segunda parte, A produção das identidades e seus quebra-cabeças, apresenta uma reflexão sobre a construção da identidade das pessoas que vivenciam o cotidiano de maneira espacial, demonstrando que, assim como o espaço, a identidade é um construto social Revista Cerrados, Montes Claros/MG, v. 18, n. 02, p. 123-151, jul./dez.-2020. 
CRUZ, U. R. X. C.

O perfil dos sujeitos sociais que compõem as redes de reciclagem do estado do Rio de Janeiro

e que ambos estão imbricados, influenciando o processo de construção e estratificação social. Isso pode explicar a posição marginal de alguns sujeitos em determinados espaços, conforme suas inter-relações ao longo de suas trajetórias.

Por fim, a terceira parte, Catadores de materiais recicláveis do estado do Rio de Janeiro, busca traçar um perfil, com base em dados quantitativos e qualitativos, dos catadores de materiais recicláveis que respondem pela coleta seletiva, pela triagem, pela classificação, pelo processamento e pela comercialização de resíduos sólidos recicláveis, exercendo eles um papel fundamental no cenário da RRERJ. Procura-se compreender, nesta parte, que, mesmo em condições precárias de trabalho, a atividade continua acontecendo, tanto nas ruas quanto nas cooperativas, como mostra a observação e a análise de dados sociais importantes como: as taxas de analfabetismo da população de catadores; as relações de gênero que existem entre esses trabalhadores e suas posições de marginalização; a relação que existe no espaço entre suas moradias e os pontos de coleta ou locais de trabalho; e outros aspectos fundamentais para o estabelecimento de seu perfil.

Portanto, a proposta deste artigo reside em compreender as relações de poder que existem nas atividades de reciclagem e catação, observando o espaço e a construção da identidade dos sujeitos que compõem a RRERJ e lhes traçando um perfil mais detalhado.

\section{METODOLOGIA: A ROTA, COM SEUS ATALHOS E CONTORNOS, DE UMA PESQUISA QUE NASCE E QUER CHEGAR A SEU DESTINO}

Esta seção apresenta o caminho metodológico percorrido durante a investigação do perfil dos catadores das redes de produção da reciclagem do estado do Rio de Janeiro. Seu propósito é descrever a atuação dos atores envolvidos e, também, os conflitos e barreiras existentes na produção da reciclagem, seja na implementação de políticas públicas, seja nos limites das ações coletivas. Além disso, pretende-se, aqui, analisar a situação socioeconômica dos catadores, a partir de dados coletados pelo Centro de Estudos Socioambientais Pangea (DAMÁSIO, 2018). A abordagem proposta abarcou um espectro amplo de processos, ações e relações sociais e espaciais, o qual exigiu diferentes procedimentos metodológicos, qualitativos e quantitativos.

Entende-se que "a metodologia científica é muito mais do que algumas regras de como fazer a pesquisa. Ela auxilia a refletir e propicia um 'novo' olhar sobre o mundo: um 
CRUZ, U. R. X. C.

O perfil dos sujeitos sociais que compõem as redes de reciclagem do estado do Rio de Janeiro

olhar científico, curioso, indagador e criativo" (GOLDENBERG, 2004, p. 11). Assim, compreende-se a metodologia não apenas como um meio ferramental que deve ser utilizado para a observação de fenômenos sociais, mas também como um mecanismo de percepção da realidade que media o processo de apreensão do conhecimento, a fim de alcançar novos olhares sobre o objeto escolhido para a pesquisa, a qual pode ser quantitativa ou qualitativa. Minayo (2007) afirma que a pesquisa qualitativa “[...] se ocupa, nas Ciências Sociais, com um nível de realidade que não pode ou não deveria ser quantificado. Ou seja, ela trabalha com o universo dos significados, dos motivos, das aspirações, das crenças, dos valores e das atitudes" (p. 21). Ramires e Pessoa (2013) acrescentam que

A pesquisa qualitativa tem como identidade o reconhecimento da existência de uma relação dinâmica entre o mundo real e o sujeito, de uma interdependência viva entre sujeito e objeto e de uma postura interpretativa, constituindo-se como um campo de atividade que possui conflitos e tensões internas. (p. 25)

Nesse sentido, para a compreensão dos conflitos e das disputas que envolvem as redes de produção da reciclagem, foi preciso, em determinado momento, utilizar recursos metodológicos de base qualitativa. Desse modo, foi possível uma aproximação mais detalhada e particular da realidade pesquisada. Na forma qualitativa de pesquisa, “[...] a preocupação do pesquisador não é com a representatividade numérica do grupo pesquisado, mas com o aprofundamento da compreensão de um grupo social, de uma organização, de uma instituição, de uma trajetória etc.” (GOLDENBERG, 2004, p. 12). A métrica quantitativa é, então, substituída pela intensidade, em uma imersão subjetiva na qual a observação é cuidadosa, por meio de entrevistas, atuação participativa e análises de diferentes fontes documentais.

Por compreender que uma pesquisa deve contemplar os enlaces econômicos, políticos, históricos e sociais que constroem as relações sociais, considerando a complexidade da realidade espacial, utilizou-se tanto de dados quantitativos provenientes das bases do Pangea, para analisar a relação capital-trabalho e a condição socioeconômica dos catadores, como de dados qualitativos oriundos da análise de documentos e, principalmente, da experiência vivida pelo pesquisador no campo da reciclagem. Nessa vivência, buscou-se compreender, a partir dos catadores, a organização espacial das redes de produção da reciclagem e os avanços e entraves que caracterizam as políticas públicas desse setor no estado do Rio de Janeiro. 
CRUZ, U. R. X. C.

O perfil dos sujeitos sociais que compõem as redes de reciclagem do estado do Rio de Janeiro

A fim de apresentar o catador e suas condições de vida, pode-se recorrer a Santos (1999), que diz que, se a desigualdade é um fenômeno socioeconômico, a exclusão é, principalmente, um fenômeno cultural e social; ela é um fenômeno de civilização. Nesse viés, a cultura se fortalece e se legitima por um discurso histórico supostamente verídico que tem por objetivo não só ditar o que precisa ser seguido, mas também rejeitar tudo aquilo que não se enquadra. Trata-se de um processo histórico pelo qual a cultura, por meio de um discurso, gera o interdito e o rejeita. Isso elucida porque os catadores são empurrados para a condição de marginalidade na sociedade e por que o lugar deles é visto como subalterno e invisível, ainda que eles desempenhem uma função de suma importância na rede de produção da reciclagem. Em vista disso, buscou-se levantar as condições socioeconômicas desses sujeitos, às quais foram atribuídos seus caráteres de exclusão e invisibilidade social.

Partiu-se, assim, do fenômeno em si, e não de sua representação, indo além das aparências e superando as primeiras impressões oferecidas pelas redes de produção e pelas políticas públicas estabelecidas para o cenário histórico e geográfico analisado. O objetivo foi reconstruir a realidade, tanto no plano abstrato quanto no retorno ao plano concreto.

\begin{abstract}
O trabalho de pesquisa, propriamente dito, a observação no campo, corresponde à grande escala e, neste nível, é somente uma parte dos fenômenos que pode ser convenientemente apreendido; os outros devem ser antevistos em escala menor e é preciso, para isto, utilizar representações que a pesquisa no terreno não pode fornecer. O trabalho de campo, para não ser somente um empirismo, deve articularse à formação teórica que é, ela também, indispensável. Saber pensar o espaço não é colocar somente os problemas no quadro local; é também articulá-los eficazmente aos fenômenos que se desenvolvem sobre extensões muito mais amplas. Não é menos verdade que a pesquisa, na medida em que ela corresponde à extração de um abstrato a partir de um concreto, pela pesquisa e pela observação de campo, dá uma grande importância ao nível de conceptualização em grande escala (evidentemente, a pesquisa pode também partir, sobretudo, das abstrações já elaboradas; a formação dos pesquisadores é então diferente e muito menos titubeante). (LACOSTE, 2006, p. 91)
\end{abstract}

Ao propor problematizar e compreender as relações estabelecidas no cenário da reciclagem, o compromisso assumido pela pesquisa foi contribuir para um olhar mais qualificado dos atores envolvidos na rede de produção da reciclagem (governos, indústrias, comerciantes, cooperativas etc.) na formulação e na implementação de ações voltadas para toda a rede e para os sujeitos que a praticam em seu cotidiano.

Dentre os documentos que foram analisados, destaca-se o relatório desenvolvido pela Secretaria Estadual do Meio Ambiente, por meio da Fundação Getúlio Vargas (FGV), e pelo Pangea, que identificou e cadastrou, em 2014, 3.084 catadores e catadoras de materiais Revista Cerrados, Montes Claros/MG, v. 18, n. 02, p. 123-151, jul./dez.-2020. 
CRUZ, U. R. X. C.

O perfil dos sujeitos sociais que compõem as redes de reciclagem do estado do Rio de Janeiro

recicláveis e realizou o diagnóstico socioeconômico de empreendimentos econômicos solidários da rede produtiva de catadores em 41 municípios do estado do Rio de Janeiro ${ }^{2}$. Desse levantamento, foi redigido um relatório em 2015 para prestação de contas, tendo este sido entregue ao Sistema de Gestão de Convênios e Contratos de Repasse do Governo Federal (SICONV).

Em outras palavras, as 3.084 pessoas entrevistadas, somadas aos dados pesquisados nas diversas fontes expressos no mapa Espacialização dos locais de residência dos catadores de materiais recicláveis da RRERJ, representam $82 \%$ da extensão territorial do estado do Rio de Janeiro, com 75 de seus municípios investigados. Em 31 desses municípios (34\%), os quais compreendem 615.600 habitantes (4\%), não existe nenhum tipo de ator da rede de reciclagem, seja indústria, comerciante, cooperativas ou mesmo catadores. Doravante, 96\% da população fluminense concentram os mesmos atores, o que revela que a pesquisa realizada pela FGV e pelo Pangea tem credibilidade, seja pelo quantitativo de entrevistados, seja pelo acesso livre em ambiente de cooperativismo e, somados, também os atores que esta pesquisa trouxe como dados coletados nas entrevistas. Concluindo, 15.374.329 habitantes representam os municípios entrevistados. Vale ressaltar, como ensina Santos (2008), que a catação está localizada na região metropolitana das capitais.

Muitos desses catadores não possuem domicílio fixo, e, mesmo os que possuem, encontram-se em locais de difícil acesso, dificultando assim o trabalho dos recenseadores. Essa perspectiva é corroborada pela literatura especializada (PORTO-GONÇALVES, 2006; BOSI, 2008; BURGOS, 2008; ROSADO, 2009; DAGNINO; DAGNINO, 2010), que destaca que a maioria dos catadores mora em periferias, em lixões ou mesmo nas ruas.

\section{CATAÇÃO E RELAÇÕES DE PODER}

A prática da reciclagem está diretamente ligada ao modo capitalista de produção. A produção massiva de bens de consumo, que alimenta a lógica de manutenção do capital

\footnotetext{
${ }^{2}$ Para o desenvolvimento do relatório, o pesquisador pôde participar tanto como funcionário, em sua execução, quanto na criação do sistema destinado a compilar as informações coletadas na pesquisa, gerando mapas e arquivos de dados. Contou-se, também, com a colaboração de 40 recenseadores que foram encarregados de realizar as visitações aos catadores de materiais recicláveis, realizando as devidas entrevistas presenciais com estrutura fechada. Nesse trabalho, com duração de seis meses, foram utilizados, como recurso metodológico, aparelhos de Global Positioning System (GPS), a fim de obter precisão quanto à localização de cada um dos catadores.
}

Revista Cerrados, Montes Claros/MG, v. 18, n. 02, p. 123-151, jul./dez.-2020. 
CRUZ, U. R. X. C.

O perfil dos sujeitos sociais que compõem as redes de reciclagem do estado do Rio de Janeiro

constante (HARVEY, 2011) e, por sua vez, o propósito de geração de lucros crescentes para os capitalistas, não se dissocia do descarte excessivo de resíduos sólidos.

Para a indústria da reciclagem, a principal justificativa para reciclar resíduos descartados provém da necessidade de se reutilizar a matéria-prima empregada em produções anteriores de mercadorias, dada a escassez de material relacionada à exploração constante de recursos (naturais), seja no presente ou por projeções de consequências futuras. Ademais, soma-se a possibilidade de aferir lucros em um novo setor de acumulação, aproveitando-se do baixo custo da matéria-prima proveniente da reciclagem de resíduos sólidos urbanos e da baixa remuneração por sua coleta. Não se pode deixar de mencionar que esse processo funciona como forma de legitimar uma rede de produção baseada nos "descartáveis", uma vez que passa a ser caracterizado como "ambientalmente correto", reduzindo oposição ou crítica social.

Simultaneamente à necessidade da indústria da reciclagem por maiores taxas de lucro, ocorre a exploração do trabalho dos catadores, responsáveis pela coleta de resíduos sólidos urbanos, bem como a incorporação de novas tecnologias, que diminuem o custo da produção e da circulação dos materiais recicláveis. Dessa maneira, colabora-se para a manutenção do ciclo da mais-valia e, por sua vez, para a acumulação de capital ${ }^{3}$.

O trabalho dos catadores de materiais recicláveis está ligado à luta por sua sobrevivência. A ausência de alternativas de trabalho formal, por sua vez, os impede de acessar determinadas esferas sociais intrínsecas à sociedade de classes. Além disso, sua prática laboral cotidiana pode ser interpretada como "ambientalista", por abarcar a coleta seletiva de resíduos sólidos urbanos e a destinação correta para eles (ROSADO, 2009).

Rosado (2009), em seu olhar sobre a realidade socialmente invisibilizada dos catadores e, mais a fundo, das catadoras de lixo, afirma que tais sujeitos, embora recorram ao uso da catação como fonte de renda, sofrem, em seu cotidiano, uma exposição exacerbada a um ciclo de exploração que os coloca em condição de marginais nas redes de relações sociais que envolvem a reciclagem. A autora define essas redes como "[...] um sistema aberto em permanente construção, que se tecem e entretecem individual e coletivamente" (p. 34). Ela

\footnotetext{
${ }^{3}$ A ideia de colaborar para a manutenção o ciclo da mais-valia e para o acúmulo de capital não indica que a atividade de catação não se apresente, para além da força de trabalho que se converte aos interesses do capital, como um ato de resistência de sujeitos marginais nas relações sociais que se instituem no sistema capitalista de produção e, por sua vez, nas cidades. Porém, ela se justifica pela noção de que, em toda relação social, há uma relação de poder e que, para haver relações de poder (sociais), há também opressão e resistência (entre diferentes sujeitos), como propõe Foucault (1995).
}

Revista Cerrados, Montes Claros/MG, v. 18, n. 02, p. 123-151, jul./dez.-2020. 
CRUZ, U. R. X. C.

O perfil dos sujeitos sociais que compõem as redes de reciclagem do estado do Rio de Janeiro

ainda pondera que a rede de reciclagem se constitui, em uma esfera em que trajetórias cotidianas se inter-relacionam,

[...] pelas conexões entre as pessoas que ocupam posições no jogo do lixo, no qual os distintos atores interagem, tendo cada nó uma posição específica e interdependente das demais no complexo campo do lixo, vivenciando um conjunto de relações econômicas, sociais, políticas e culturais que dele emergem. (p. 34)

A compreensão do conceito de rede, que a autora assume para sua discussão, parte da noção de que as redes são constituídas por relações de poder, que, através da comunicação, trocam significados que se materializam nos enlaces produzidos pelos e entre os atores, os quais, por sua vez, permitem a circulação desses significados, a partir das práticas espaciais materializadas no cotidiano. Tal relação entre rede e poder é também trazida à baila por Raffestin (1993), para o qual

É conveniente, pois, decifrar as redes por meio de sua história e do território no qual estão instaladas, por meio dos modos de produção que permitiram a sua instalação e das técnicas que lhes deram forma. As redes são não somente a exibição do poder, mas são ainda feitas à imagem do poder. (p. 209)

Assim como Raffestin (1993), Rosado (2009) define a rede como parte integrante de um território, espaço este constituído por e a partir de relações de poder (SOUZA, 2013). Desse modo, é compreensível que a rede social de reciclagem, da qual trata Rosado (2009), seja constituída por relações de poder e, da mesma forma, por conflitos que partem de diferentes atores, que constituem a lógica da produção da reciclagem de resíduos sólidos urbanos.

Segundo Foucault (1995), o conceito de poder refere-se a um agrupamento de práticas e ações que são correspondentes umas às outras. Para o autor, não se trata de um exercício unilateral de alguém sobre algo ou outro alguém, mas de um conjunto de atos que partem de diferentes polos. Tais atos não ocorrem de maneira unidirecional e dependem da aceitação e/ou da resistência dos diferentes atores que constituem as relações sociais.

Sobre a necessidade de trazer à tona os discursos dos principais atores da rede de reciclagem, Silva (2017) elucida que, por vezes, a relação de trabalho é tensionada mediante o empoderamento dos catadores. Lussari (2016) atinge uma compreensão um pouco além das cooperativas como elementos importantes para o empoderamento dos trabalhadores relacionados à coleta seletiva, porém caminha no entendimento de que transformar a força de 
CRUZ, U. R. X. C.

O perfil dos sujeitos sociais que compõem as redes de reciclagem do estado do Rio de Janeiro

trabalho individual em coletiva colabora para o fortalecimento do discurso dos trabalhadores perante a rede de reciclagem. Conforme ele destaca,

Ao discutir-se a emergência de uma cultura organizacional em uma cooperativa de recicladores de resíduos sólidos, cujos cooperados são oriundos de um estado de trabalho diferente do necessário, para se estabelecer na nova ocupação, há a necessidade de se entender todo o contexto histórico, social e político, de forma a estabelecer um lugar, um território e um espaço, em que se crie uma nova identidade do trabalhador. (p. 184)

Como demonstram não apenas Dagnino e Dagnino (2010), mas também outros autores, como Costa e Chaves (2012) e Bosi (2008), a organização dos catadores envolvidos na rede de produção da reciclagem de resíduos sólidos urbanos se insere, por meio de cooperativas, no campo de lutas para a visibilidade dos trabalhadores da catação, direcionadas ao fomento de políticas públicas que os envolvam.

Fato é que as redes de produção da reciclagem se perfazem em diferentes escalas geográficas (global, nacional, regional e urbana), em que a lógica capitalista da indústria de reciclagem se (re)produz, destarte, tendo relação direta com a situação econômica, política e espacial dos sujeitos e atores que a constituem nas cidades (escala intraurbana). Assim, afirma Rosado (2009) que a posição de mediado e mediador na rede de reciclagem depende justamente da compreensão discursiva dos sujeitos que constituem essa rede, ou seja, da condição social na qual os sujeitos se inserem.

Não podemos partir do pressuposto que todos os agentes envolvidos (mediadores e mediados) possuem a mesma condição de entendimento, pois o mediador assume esse papel, justamente, pela dificuldade do mediado em relacionar-se com outros jogos de linguagem, ou seja, o mediador somente tem razão de existir na relação se for para cumprir este papel. [...] É mais interessante para o grupo social que o mediador atribua validade ao seu discurso (em diferentes meios) e que procure traduzi-lo no discurso do outro. Assim, na prática mediadora, pode-se perceber uma "violência simbólica" pela subjugação da cultura, do entendimento acerca do mundo, do próprio mediado. (ROSADO, 2009, p. 110)

A posição de Rosado (2009) colabora para a compreensão de que há, em uma rede de reciclagem, práticas e ações desiguais entre os atores, devido à posição social em que estes se situam. Os catadores de materiais recicláveis, particularmente os catadores de ruas, constroem suas vivências na condição de sujeitos mediados em subordinação aos atravessadores e, não obstante, na ausência de cooperativas ou galpões de reciclagem de resíduos sólidos urbanos, ainda que estes últimos envolvam outro tipo de relação de poder. 
CRUZ, U. R. X. C.

O perfil dos sujeitos sociais que compõem as redes de reciclagem do estado do Rio de Janeiro

\section{A PRODUÇÃO DAS IDENTIDADES E SEUS QUEBRA-CABEÇAS}

Os sujeitos sociais ou, em outros termos, as pessoas que vivenciam o cotidiano de maneira espacial se constituem de maneira identitária. É importante destacar que, assim como o espaço, a identidade é um construto social. Isso significa que, assim como o conceito anteriormente abordado, a identidade não se estabelece de maneira pré-discursiva aos sujeitos. Segundo Bauman (2005), as identidades dos sujeitos são como um quebra-cabeça, sem manual de montagem e com peças faltantes, sendo, então, de complexa compreensão e permanentemente incompletas. Para ele, a identidade é resultante de uma história em constante construção, porém não linear, da vida dos seres humanos (sociais), com mudanças ao longo de suas trajetórias, compreendendo diversos marcadores, como raça, gênero, etnia, classe de renda e sexualidade. Vale destacar que

[...] A "identidade" só nos é revelada como algo a ser inventado, e não descoberto; como alvo de um esforço, "um objetivo"; como uma coisa que ainda se precisa construir a partir do zero ou escolher entre alternativas e então lutar por ela e protegê-la lutando ainda mais. (BAUMAN, 2005, p. 21)

Bauman (2005) ainda argumenta que o processo de identificação de um sujeito, isto é, de sua constituição identitária colabora para a estratificação social, destacando, então, os sujeitos em relação a seus feixes identitários, identificando-os conforme esses feixes. Tais feixes correspondem muitas vezes a "padrões" hegemônicos, levando, por conseguinte, à marginalização de certas pessoas em determinadas escalas espaciais.

Outro autor que estabelece uma discussão acerca do conceito de identidade é Hall (2011). Ele, assim como Bauman (2005), contempla a identidade como um produto social. Para ele, as identidades, assim como o espaço, não se estabelecem nunca de maneira fixa, sendo maleáveis e mutáveis. A identidade, em seus termos, "é definida historicamente, e não biologicamente. O sujeito assume identidades diferentes em diferentes momentos identidades que não são unificadas ao redor de um 'eu' coerente" (p. 13). É possível perceber que as concepções desses dois autores confluem. Ambos consideram a identidade como uma instituição de sujeitos sociais que, de modo discursivo, isto é, por meio de suas relações sociais e espaciais, a constroem em movimentos de constantes mudanças e adaptações, conforme a realidade em que se inserem. O modo pelo qual as pessoas se estabelecem 
CRUZ, U. R. X. C.

O perfil dos sujeitos sociais que compõem as redes de reciclagem do estado do Rio de Janeiro

enquanto sujeitos, isto é, pelo qual assumem posturas identitárias, é um componente fundamental das relações espaciais.

Diante disso, é válido o retorno ao que foi apresentado anteriormente, embasandoo em Massey (2008) e Corrêa (2000), que trazem à baila uma compreensão do conceito geográfico de espaço enquanto um construto social instituído a partir de inter-relações dos sujeitos. O ponto culminante entre esses autores e os outros dois, citados anteriormente, localiza-se na afirmação de que, geograficamente, os sujeitos, enquanto seres sociais/identitários, não podem ser vistos para além de uma escala espacial. Isso significa que a existência desses sujeitos é espacial e, não obstante, geográfica.

Quando se parte de uma perspectiva de espaço, como a que foi até agora defendida, é necessário carregar uma definição de que, se o espaço é social, como são também as identidades, ele é composto de histórias que se constituem de maneira não linear, ainda que carregadas de significados reafirmados em detrimento de outros negados, pelos sujeitos que o instituem. Nesse viés, é possível evocar o argumento de Pollack (1992) sobre a memória identitária/social dos indivíduos/sujeitos enquanto seu componente sociocultural.

Para ele, a identidade de um sujeito pode ser considerada como uma visualização de cada um sobre si mesmo e para outrem. Ademais, apesar de se constituir como uma apreensão do indivíduo, ele também se estabelece de maneira externa a esse, ou seja, dependendo da aprovação do círculo social em que se insere. Nas palavras do autor, "a construção da identidade é um fenômeno que se produz em referência aos outros, em referência aos critérios de aceitabilidade, de admissibilidade, de credibilidade, e que se faz por meio da negociação direta com outros" (p. 204).

Ainda com base em Pollack (1992), no que se refere à forma como a identidade se apresenta a partir do diálogo do interno para com o externo de cada indivíduo, a memória social/identitária é constituída das interrelações do sujeito ao longo de suas trajetórias nas mais diversas escalas, embora lhe seja exclusiva e específica. Pelo caráter exclusivo e específico da memória social/identitária, deve-se entender que esta é resultante da apreensão de cada sujeito acerca do real, bem como da maneira como cada um institui o espaço, que é também a mesma forma pela qual o espaço se institui, segundo a perspectiva assumida para esta reflexão. 
CRUZ, U. R. X. C.

O perfil dos sujeitos sociais que compõem as redes de reciclagem do estado do Rio de Janeiro

\section{CATADORES DE MATERIAIS RECICLÁVEIS DO ESTADO DO RIO DE JANEIRO}

Os catadores de materiais recicláveis são trabalhadores responsáveis pela coleta seletiva, pela triagem, pela classificação, pelo processamento e pela comercialização de resíduos sólidos recicláveis, exercendo eles um papel fundamental no cenário da RRERJ. Ainda que suas condições de trabalho sejam muito precárias, a atividade pode acontecer tanto de maneira autônoma, nas ruas das cidades ou nos lixões, como de maneira mais organizada, em cooperativas e associações. A atividade foi reconhecida pelo Ministério do Trabalho e Emprego em 2002, constando, a partir de então, na Classificação Brasileira de Ocupações (CBO) (MINISTÉRIO DO TRABALHO E EMPREGO, 2010).

De acordo com as estimativas do Movimento Nacional dos Catadores de Materiais Recicláveis (MNCR), existem no Brasil cerca de 800 mil trabalhadores atuando como catadores de materiais recicláveis (MOVIMENTO NACIONAL DOS CATADORES DE MATERIAIS RECICLÁVEIS, 2019). Esse número, no entanto, diverge do que foi levantado pelo Instituto Brasileiro de Geografia e Estatística (IBGE) no Censo Demográfico de 2010, o qual é menor, não chegando nem à metade do referido (INSTITUTO BRASILEIRO DE GEOGRAFIA E ESTATÍSTICA, 2012).

Do montante de catadores brasileiros levantado pelo IBGE, 66,1\% se reconhecem como negros (INSTITUTO DE PESQUISA ECONÔMICA APLICADA, 2013). Isso significa que, a cada três catadores de materiais recicláveis, dois se consideram negros. Ao comparar esse dado com a informações do Censo de 2010 que revela que $52,0 \%$ dos brasileiros são negros, constata-se que o percentual de catadores negros chega a ser superior ao percentual de negros da própria população brasileira, segundo o levantamento que levou em consideração a autodeclaração de pretos e pardos (INSTITUTO BRASILEIRO DE GEOGRAFIA E ESTATÍSTICA, 2012).

Conforme um relatório acerca do Sudeste do Brasil publicado em 2013 como parte da série Situação Social das Catadoras e dos Catadores de Material Reciclável e Reutilizável ${ }^{4}$, esta região concentra 116.417 catadores. Desse montante, aproximadamente $70 \%$ correspondem a homens. Quanto ao Rio de Janeiro, este conta com um quantitativo de

\footnotetext{
${ }^{4}$ A série Situação Social das Catadoras e dos Catadores de Material Reciclável e Reutilizável foi uma iniciativa da Diretoria de Estudos e Políticas Sociais (DISOC) do Instituto de Pesquisa Econômica Aplicada (IPEA), em parceria com a Secretaria Geral da Presidência da República e com a Secretaria Nacional de Economia Solidária (SENAES) do Ministério do Trabalho e Emprego.

Revista Cerrados, Montes Claros/MG, v. 18, n. 02, p. 123-151, jul./dez.-2020.
} 
CRUZ, U. R. X. C.

O perfil dos sujeitos sociais que compõem as redes de reciclagem do estado do Rio de Janeiro

36.238 catadores e catadoras de materiais recicláveis. Nesse estado, segundo os dados do mesmo relatório, $27,7 \%$ dos catadores do Brasil têm entre 0 e 29 anos de idade, 48,1\%, entre 30 e 75 anos e $21 \%$, entre 76 e 100 anos de idade (INSTITUTO DE PESQUISA ECONÔMICA APLICADA, 2013). Isso evidencia que, entre os fluminenses, mais da metade dessa classe é composta por adultos, estando muitos deles em idade avançada, tratando-se de uma população majoritariamente idosa.

Em relação ao gênero, a realidade fluminense não é diferente da dos outros estados do Sudeste. No Rio de Janeiro, é predominante o número de homens que exercem a catação, contando com $78,2 \%$ do total de trabalhadores, enquanto as mulheres representam apenas $21,8 \%$. No que tange à raça, nesse estado, a população de catadores é composta majoritariamente por negros, com $72,7 \%$, enquanto os brancos constituem apenas $27,3 \%$ (INSTITUTO DE PESQUISA ECONÔMICA APLICADA, 2013).

O relatório também revela que a coleta e a reciclagem de resíduos sólidos são atividades essencialmente urbanas, já que seu percentual é de 93,3\% em todo o país, chegando a 96,4\% apenas no estado do Rio de Janeiro. Isso se explica pelo fato de essas atividades dependerem do descarte, o qual, em áreas rurais, é praticamente nulo, correspondendo a 3,6\% somente (INSTITUTO DE PESQUISA ECONÔMICA APLICADA, 2013).

Outro dado interessante diz respeito à renda do catador, que, segundo as informações do Censo Demográfico do IBGE, era, em 2010, de R\$ 571,56 em média (INSTITUTO BRASILEIRO DE GEOGRAFIA E ESTATÍSTICA, 2012). Nesse ano, vale lembrar, o salário mínimo era de $\mathrm{R} \$ 510,00$. No estado do Rio de Janeiro, por sua vez, os trabalhadores informaram ter uma renda média de $\mathrm{R} \$ 653,15$, sendo este o maior valor entre os estados do Sudeste brasileiro (INSTITUTO DE PESQUISA ECONÔMICA APLICADA, 2013).

Embora não haja meios de atestar a veracidade das declarações dos catadores, o Censo de 2010 revelou que 57,9\% dos trabalhadores contribuíam para a previdência, enquanto, no estado do Rio de Janeiro, esse número se mostrou ainda mais expressivo, contando com $74,4 \%$ dos entrevistados. Já quanto aos dados referentes à cobertura da população idosa (60 anos ou mais), sobre os benefícios previdenciários e assistenciais, os números mostraram que a maior parte se encontrava descoberta, não usufruindo de qualquer seguridade, estando, assim, em uma condição de vulnerabilidade social. Considerando todo o 
CRUZ, U. R. X. C.

O perfil dos sujeitos sociais que compõem as redes de reciclagem do estado do Rio de Janeiro

território nacional, apenas 57,8\% contavam com a cobertura de aposentadoria, enquanto, no estado do Rio de Janeiro, o número era ainda menor, com apenas 53,0\% dos entrevistados (INSTITUTO DE PESQUISA ECONÔMICA APLICADA, 2013).

Outro dado social preocupante diz respeito ao analfabetismo. De acordo com o Censo de 2010, esse número chegava a 9,4\% do total da população nacional e, entre os catadores de materiais recicláveis, ele era maior, beirando os $20,5 \%$, sendo que, no estado do Rio de Janeiro, a pesquisa revelou um quantitativo de 10,2\%. Enquanto o território nacional apresenta 50,3\% da população com ensino fundamental completo, com 25 anos ou mais, quando se trata dos trabalhadores da reciclagem este número cai para 24,6\%. No Rio de Janeiro, apenas 38,3\% dos catadores concluíram o ensino fundamental. Em relação ao ensino médio completo, 35,9\%, da população brasileira tinha essa escolaridade, porém, entre os catadores, o número geral era de $11,4 \%$ e o número local, referente ao Rio de Janeiro, de 20,0\% (INSTITUTO DE PESQUISA ECONÔMICA APLICADA, 2013).

O gráfico a seguir (Gráfico 1) mostra a estimativa de gênero dos trabalhadores da RRERJ. Para gerá-lo, utilizou-se o relatório anteriormente mencionado, que, como dito, foi desenvolvido pela FGV e pelo Pangea.

\section{Gráfico 1 - Gênero dos sujeitos que compõem a RRERJ}

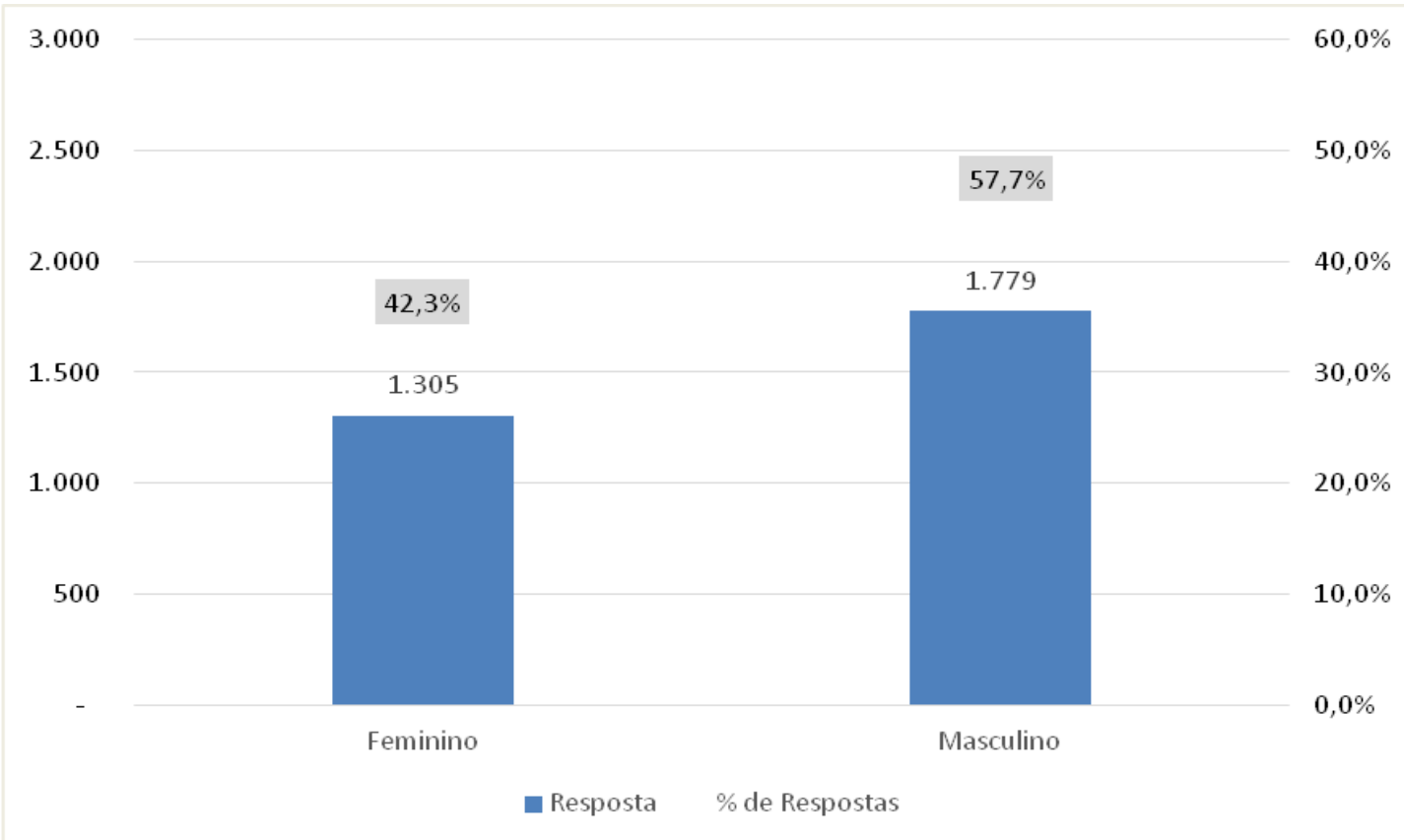

Fonte: Questionários aplicados pelo pesquisador no estudo realizado pela FGV e pelo Pangea e atualizados por meio do software CATAsig. Gráfico elaborado pelo autor, 2018. 
CRUZ, U. R. X. C.

O perfil dos sujeitos sociais que compõem as redes de reciclagem do estado do Rio de Janeiro

Conforme o Gráfico 1, da população total em que o questionário foi aplicado (3.084 sujeitos), a maioria é constituída por pessoas do gênero masculino, com 1.779 pessoas, seguido de 1.305 pessoas do gênero feminino. Isso significa que a maioria dos sujeitos que compõem o cenário da catação, vivenciando a rede e seu cotidiano, são homens. Nesse seguimento, percebe-se que tal atividade ainda é majoritariamente masculina, com $57,7 \%$ do total, ainda que as mulheres também estejam bem representadas, com 42,3\%, e a diferença entre os gêneros não seja grande.

Devido ao percentual de homens catadores ser maior, é possível inferir que esses sujeitos imprimem em suas relações significados de vivências cotidianas correspondentes a esse aspecto que se relaciona à noção de gênero, que, assim como outros traços identitários, corresponde a padrões assumidos socialmente como hegemônicos ao longo de uma história social.

Isso significa que, muito embora hegemonicamente se possa considerar a sociedade enquanto patriarcal — isto é, como uma sociedade em que os homens se colocam de maneira central em relação às mulheres, as quais, por sua vez, são colocadas à margem —, os homens que compõem a realidade da catação são muitas vezes marginalizados quando dispostos em relação a outros homens ou, até mesmo, outras mulheres que não experimentam a mesma realidade social deles. Isso ocorre porque os traços identitários se relacionam entre si, e, a depender da interseção entre eles, os sujeitos podem intensificar ou não suas condições centrais e/ou marginais em suas relações sociais/espaciais.

Outros traços identitários podem ser relacionados a esses sujeitos, como os que são destacados nos gráficos a seguir (Gráfico 2 e Gráfico 3). Como foi comentado anteriormente, esses traços são intersecionados uns aos outros, não sendo, pois, vivenciados espacialmente de maneira individual, mas em correlação constante. Assim, ao passo que os sujeitos se identificam como homens e mulheres, eles não limitam suas identidades a esses traços, mas também os apreendem a partir de outros aspectos. 
CRUZ, U. R. X. C.

O perfil dos sujeitos sociais que compõem as redes de reciclagem do estado do Rio de Janeiro

\section{Gráfico 2 - Grau de instrução escolar entre os componentes da RRERJ}

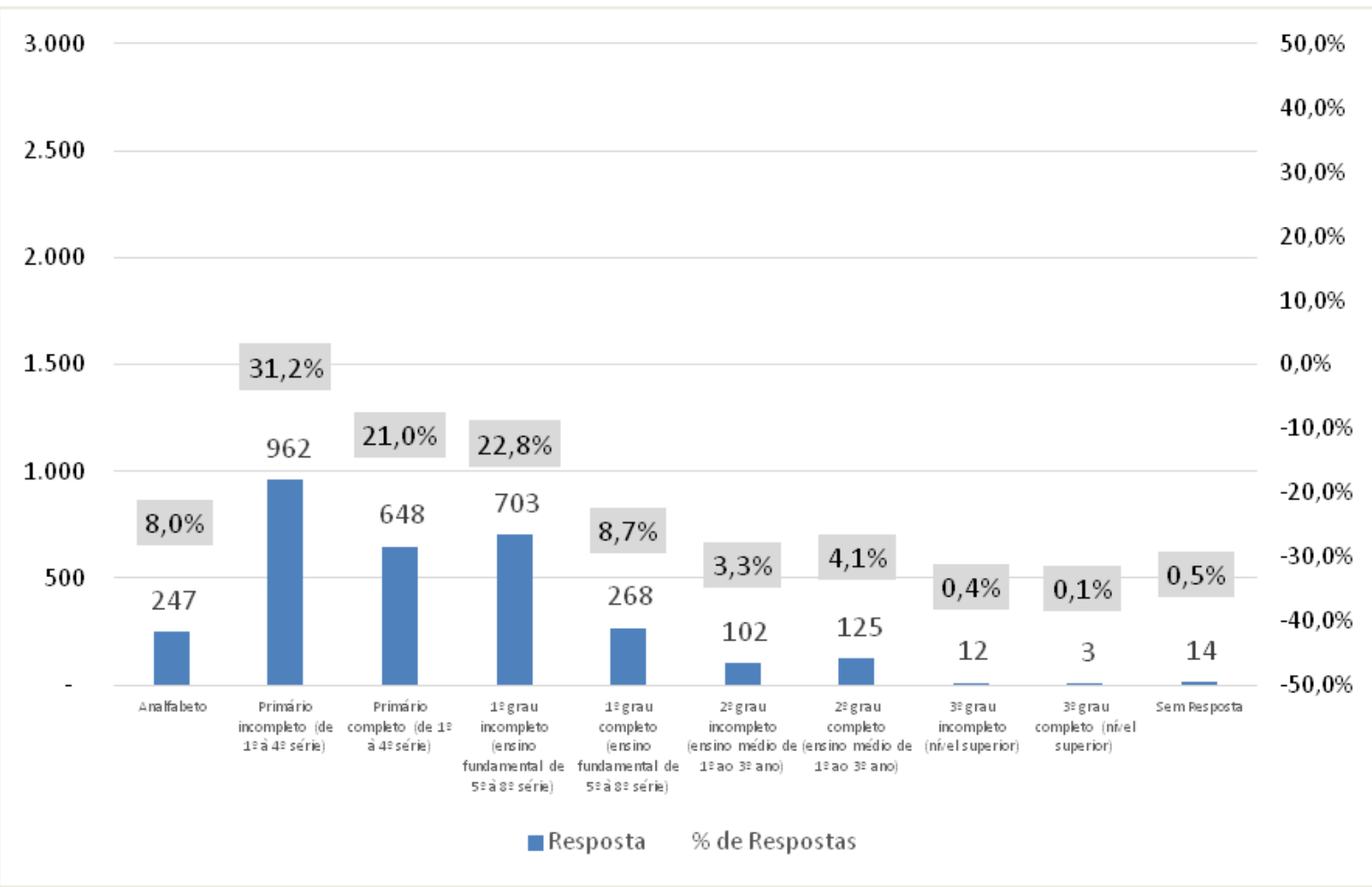

Fonte: Questionários aplicados pelo pesquisador no estudo realizado pela FGV e pelo Pangea e atualizados por meio do software CATAsig. Gráfico elaborado pelo autor, 2018.

Um resultado importante que vale ser ressaltado corresponde ao universo de pessoas cujo nível de escolarização é, no máximo, o ensino fundamental completo. Das 3.084 pessoas questionadas, o maior número se refere a sujeitos cujo grau de instrução é o primário

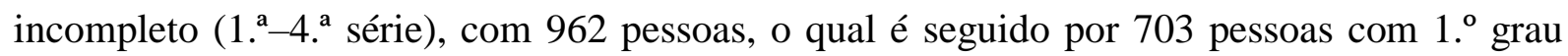

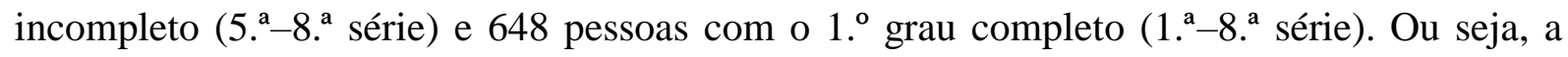
maioria dos entrevistados não tinha terminado o ensino básico, totalizando $95 \%$. Um terço deles, aliás, não tinha sequer completado a primeira fase do ensino fundamental.

O mercado profissional no sistema capitalista convoca os sujeitos à superespecialização e ao alto grau de escolarização, para que eles possam compor o circuito superior da economia. Por possuírem baixa instrução educacional, os catadores têm suas vivências relacionadas ao circuito inferior da economia, caracterizado pela ausência de políticas públicas de reparação das desigualdades, de saúde, de moradia e de educação pública de qualidade. 
CRUZ, U. R. X. C.

O perfil dos sujeitos sociais que compõem as redes de reciclagem do estado do Rio de Janeiro

Em outros termos, o abandono do Estado se faz presente nesse grupo. É interessante essa análise porque quando se relaciona a negação do acesso à escolarização básica, que é pública, laica, de qualidade e direito de todos, com as classes subalternizadas, percebe-se que suas marginalidades são significadas por esses fatores, bem como pelo gênero e pela raça, por exemplo, que são perpetuados segundo uma lógica de exclusão.

O Gráfico 3 trata da declaração de raça dos catadores. Tal questão identitária é componente da marginalidade dos sujeitos no espaço geográfico, especialmente na sociedade racista-colonial. Percebe-se, pelos dados obtidos, que a sociedade ainda empurra os negros para atividades laborais que os mantêm à margem da sociedade, em situação trabalhista desfavorável e menos remunerada.

\section{Gráfico 3 - Raça entre os componentes da RRERJ}

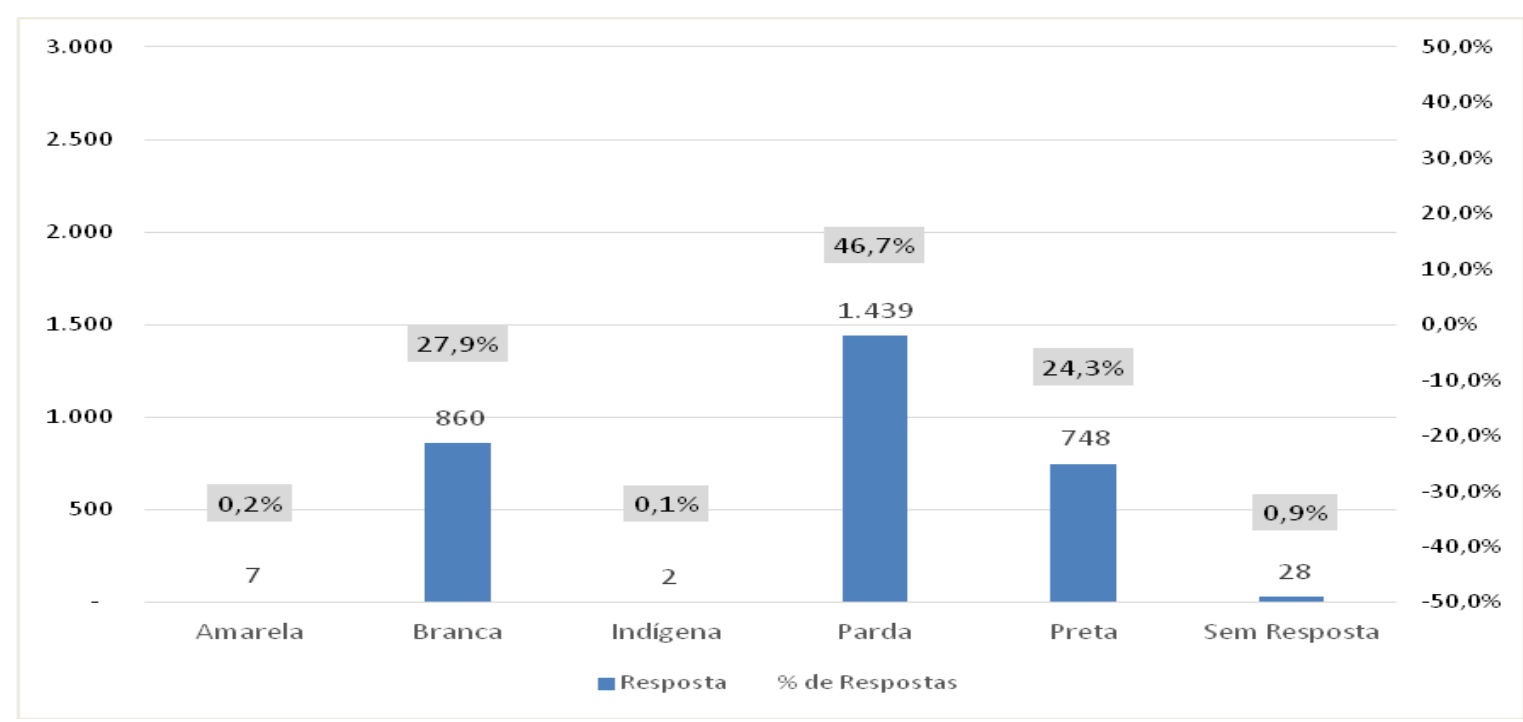

Fonte: Questionários aplicados pelo pesquisador no estudo realizado pela FGV e pelo Pangea e atualizados por meio do software CATAsig. Gráfico elaborado pelo autor, 2018.

Fatores como a raça, o gênero e a escolaridade possuem um alto teor simbólico e dizem mais do que aparentam mostrar. A raça, por exemplo, se apresenta também enquanto um construto social que colabora para a condição dos sujeitos enquanto centrais ou marginais. Estabelecendo como base para a população brasileira a noção de raça do IBGE, a maioria dos trabalhadores ligados à rede de produção do Rio de Janeiro é sumariamente autodeclarada negra, já que o que se define como população negra consiste no somatório entre pretos e pardos, e este equivale a aproximadamente $71 \%$ da população total. Trata-se, então, de uma 
CRUZ, U. R. X. C.

O perfil dos sujeitos sociais que compõem as redes de reciclagem do estado do Rio de Janeiro

rede composta por homens negros com baixo grau de instrução escolar. Por esse aspecto, os componentes da RRERJ, que, por sua vez, integram o circuito inferior da economia, correspondem a um recorte populacional que, nas mais diversas escalas, são alvo de segregação/marginalização devido a suas características identitárias.

O Rio de Janeiro é a segunda cidade com maior quantidade de brasileiros que se declaram negros e pardos. São três milhões ao todo. Segundo o IBGE, entre 2012 e 2016, enquanto a população brasileira cresceu 3,4\%, chegando a 205,5 milhões, o número dos que se declaravam brancos teve uma redução de 1,8\%, totalizando 90,9 milhões. Já o número de pardos autodeclarados cresceu 6,6\% e o de pretos, 14,9\%, chegando a 95,9 milhões e 16,8 milhões, respectivamente (INSTITUTO BRASILEIRO DE GEOGRAFIA E ESTATÍSTICA, 2017). No Censo de 2010, a população do Rio de Janeiro era formada por 3.239.888 brancos, com 51,26\%, 2.318.675 pardos, com 36,69\%, 708.148 pretos, com 11,2\%, 45.913 amarelos e 5.981 indígenas, com $0,09 \%$, e 1.842 sem declaração, com $0,03 \%$.

\section{Gráfico 4 - Faixa etária dos componentes da RRERJ em 2014}

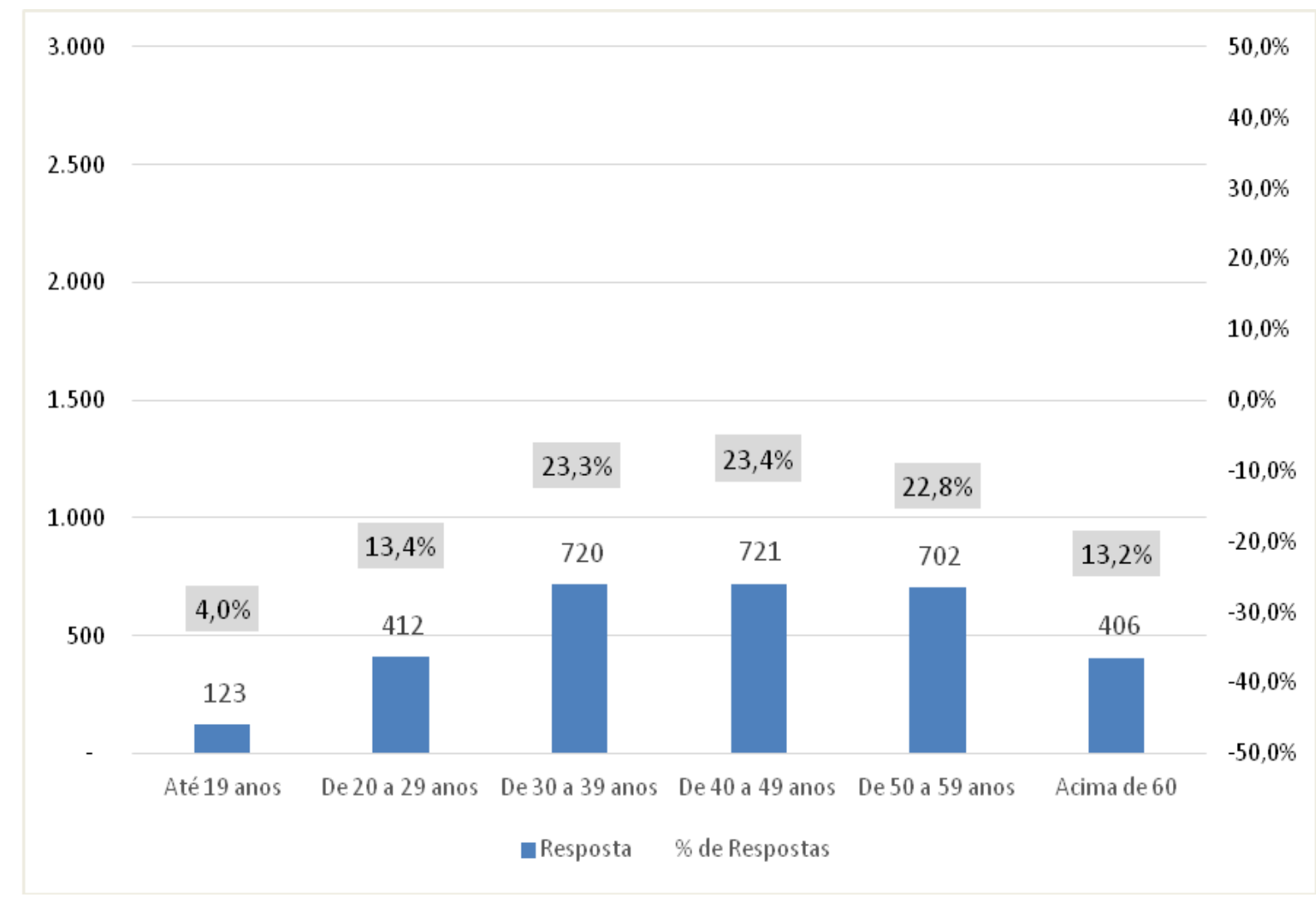

Fonte: Questionários aplicados pelo pesquisador no estudo realizado pela FGV e pelo Pangea e atualizados por meio do software CATAsig. Gráfico elaborado pelo autor, 2018.

Revista Cerrados, Montes Claros/MG, v. 18, n. 02, p. 123-151, jul./dez.-2020. 
CRUZ, U. R. X. C.

O perfil dos sujeitos sociais que compõem as redes de reciclagem do estado do Rio de Janeiro

Outro aspecto que merece destaque é a faixa etária, que, em sua grande maioria, compreende catadores que tenham entre 30 e 60 anos de idade $(69,5 \%$ do total de entrevistados), estando estes inseridos na idade adulta. Do quantitativo total, constam 721 pessoas entre 40 e $50 \operatorname{anos}(23,4 \%), 702$ pessoas entre 50 e 60 anos $(22,8 \%)$ e 641 pessoas entre 30 e 40 anos de idade (23,3\%). Observando os dados, percebe-se que $20 \%$ dos catadores têm idade acima dos 60 anos, o que chama a atenção para o desemprego na terceira idade ou a ausência de acesso a recursos de aposentadoria da Previdência Social que supram, de modo parcial ou completamente, os gêneros de primeira necessidade dos aposentados e de suas famílias, como água, luz, moradia, alimentação e saúde. Assim como os idosos se veem obrigados a voltar ao mercado de trabalho da forma que conseguem, os jovens também são despejados no universo da produção da reciclagem, com 123 sujeitos abaixo de 19 anos, o que pode, dependendo da idade, implicar inclusive em trabalho infantil. Elencados e ilustrados esses pontos, pode-se avançar para a questão da moradia dos catadores de materiais recicláveis da RRERJ.

\section{Quadro 1 - Síntese dos catadores de matérias recicláveis da RRERJ por município:} residência vs. situação de rua, em 2014

\begin{tabular}{|l|cc|cc|c|}
\hline Cidade & Morador de rua & $\%$ & Residência & $\%$ & Total \\
\hline Angra dos Reis & 3 & $8 \%$ & 36 & $92 \%$ & 39 \\
\hline Araruama & 5 & $8 \%$ & 54 & $92 \%$ & 59 \\
\hline Armação de Búzios & 0 & $0 \%$ & 3 & $100 \%$ & 3 \\
\hline Arraial do Cabo & 0 & $0 \%$ & 53 & $100 \%$ & 53 \\
\hline Barra Mansa & 4 & $6 \%$ & 66 & $94 \%$ & 70 \\
\hline Belford Roxo & 5 & $7 \%$ & 71 & $93 \%$ & 76 \\
\hline Bom Jesus do Itabapoana & 2 & $7 \%$ & 27 & $93 \%$ & 29 \\
\hline Bom Sucesso & 0 & $0 \%$ & 1 & $100 \%$ & 1 \\
\hline Búzios & 0 & $0 \%$ & 22 & $100 \%$ & 22 \\
\hline Cabo Frio & 7 & $3 \%$ & 211 & $97 \%$ & 218 \\
\hline Duque de Caxias & 150 & $17 \%$ & 700 & $83 \%$ & 850 \\
Iguaba Grande & 0 & $0 \%$ & 5 & $100 \%$ & 5 \\
\hline Itaboraí & 3 & $5 \%$ & 60 & $95 \%$ & 63 \\
\hline Itaguaí & 2 & $4 \%$ & 50 & $96 \%$ & 52 \\
\hline Itaperuna & 3 & $12 \%$ & 23 & $88 \%$ & 26 \\
\hline Itatiaia & 0 & $0 \%$ & 17 & $100 \%$ & 17 \\
\hline Japeri & 9 & $16 \%$ & 46 & $84 \%$ & 55 \\
\hline Macaé & 16 & $10 \%$ & 140 & $90 \%$ & 156 \\
\hline Magé & 2 & $3 \%$ & 31 & $97 \%$ & 32 \\
\hline Maricá & & $13 \%$ & 14 & $88 \%$ & 16 \\
\hline
\end{tabular}

Revista Cerrados, Montes Claros/MG, v. 18, n. 02, p. 123-151, jul./dez.-2020. 
CRUZ, U. R. X. C.

O perfil dos sujeitos sociais que compõem as redes de reciclagem do estado do Rio de Janeiro

\begin{tabular}{|c|c|c|c|c|c|c|}
\hline Mesquita & 7 & $10 \%$ & 60 & $90 \%$ & & 67 \\
\hline Nilópolis & 2 & $2 \%$ & 91 & $98 \%$ & & 93 \\
\hline Niterói & 20 & $18 \%$ & \multicolumn{2}{|c|}{91} & & 111 \\
\hline Nova Iguaçu & 5 & $5 \%$ & \multicolumn{2}{|c|}{94} & & 99 \\
\hline Paracambi & 2 & $6 \%$ & \multicolumn{2}{|c|}{31} & & 33 \\
\hline Paraíba do Sul & 1 & $5 \%$ & \multicolumn{2}{|c|}{19} & & 20 \\
\hline Paraty & 1 & $17 \%$ & \multicolumn{2}{|c|}{5} & & 6 \\
\hline Pedreira & 0 & $0 \%$ & \multicolumn{2}{|c|}{1} & & 1 \\
\hline Petrópolis & 2 & $8 \%$ & \multicolumn{2}{|c|}{22} & & 24 \\
\hline Queimados & 12 & $16 \%$ & \multicolumn{2}{|c|}{63} & & 75 \\
\hline Resende & 2 & $3 \%$ & \multicolumn{2}{|c|}{61} & & 63 \\
\hline Rio Bonito & 1 & $8 \%$ & \multicolumn{2}{|c|}{11} & & 12 \\
\hline Rio das Ostras & 1 & $2 \%$ & \multicolumn{2}{|c|}{51} & & 52 \\
\hline Rio das Pedras & 0 & $0 \%$ & \multicolumn{2}{|c|}{3} & & 3 \\
\hline Santo Antonio de Pádua & 2 & $6 \%$ & \multicolumn{2}{|c|}{29} & & 31 \\
\hline São Fidelis & 1 & $6 \%$ & \multicolumn{2}{|c|}{15} & & 16 \\
\hline São Gonçalo & 33 & $23 \%$ & \multicolumn{2}{|c|}{111} & & 144 \\
\hline São João de Meriti & 6 & $7 \%$ & \multicolumn{2}{|c|}{76} & & 82 \\
\hline São Pedro da Aldeia & 1 & $1 \%$ & \multicolumn{2}{|c|}{71} & & 72 \\
\hline Saquarema & 3 & $8 \%$ & \multicolumn{2}{|c|}{44} & & 47 \\
\hline Seropédica & 8 & $22 \%$ & 29 & $78 \%$ & & 37 \\
\hline Tanguá & 0 & $0 \%$ & 22 & $100 \%$ & & 22 \\
\hline Três Rios & 0 & $0 \%$ & \multicolumn{2}{|c|}{33} & & 33 \\
\hline Volta Redonda & 16 & $12 \%$ & \multicolumn{2}{|c|}{119} & & 135 \\
\hline Total & 288 & $9 \%$ & \multicolumn{2}{|c|}{2.796} & & 3.084 \\
\hline \multicolumn{2}{|l|}{ Cidades } & Morador de rua & $\%$ & Residência & $\%$ & Total \\
\hline \multicolumn{2}{|c|}{ Região Metropolitana do Rio de Janeiro } & 218 & $12 \%$ & 1.646 & $88 \%$ & 1.864 \\
\hline \multicolumn{2}{|l|}{ Demais Cidades } & 70 & $6 \%$ & 1.150 & $94 \%$ & 1.220 \\
\hline \multicolumn{2}{|l|}{ Total } & 288 & $9 \%$ & 2796 & $91 \%$ & 3.084 \\
\hline
\end{tabular}

Fonte: Questionários aplicados pelo pesquisador no estudo realizado pela FGV e pelo Pangea. Quadro elaborado pelo autor, 2018.

Conforme o estudo realizado pela FGV e pelo PANGEA ${ }^{5}$, o município de Duque de Caxias representa o maior quantitativo de catadores das redes de reciclagem do Rio de Janeiro, com 850 indivíduos com residência (87\%) e 100 sem residência fixa no município (13\%). Em síntese, as cooperativas que estão na região metropolitana do Rio de Janeiro apresentam os maiores índices de catadores com e sem moradia fixa, o que está diretamente ligado à questão populacional dos municípios. A pesquisa confirma que 88\% (1.646) dos catadores da região metropolitana do Rio de Janeiro possuem moradia fixa e 12\% (218) não.

\footnotetext{
${ }^{5}$ Estudo realizado considerando 44 municípios do estado do Rio de Janeiro.
} 
CRUZ, U. R. X. C.

O perfil dos sujeitos sociais que compõem as redes de reciclagem do estado do Rio de Janeiro

Quanto às demais cidades, estas abarcam 94\% (1.150) dos catadores com moradia fixa e somente $6 \%$ (70) em situação de rua.

\section{Gráfico 5 - Motivos pelos quais os sujeitos trabalham com catação.}

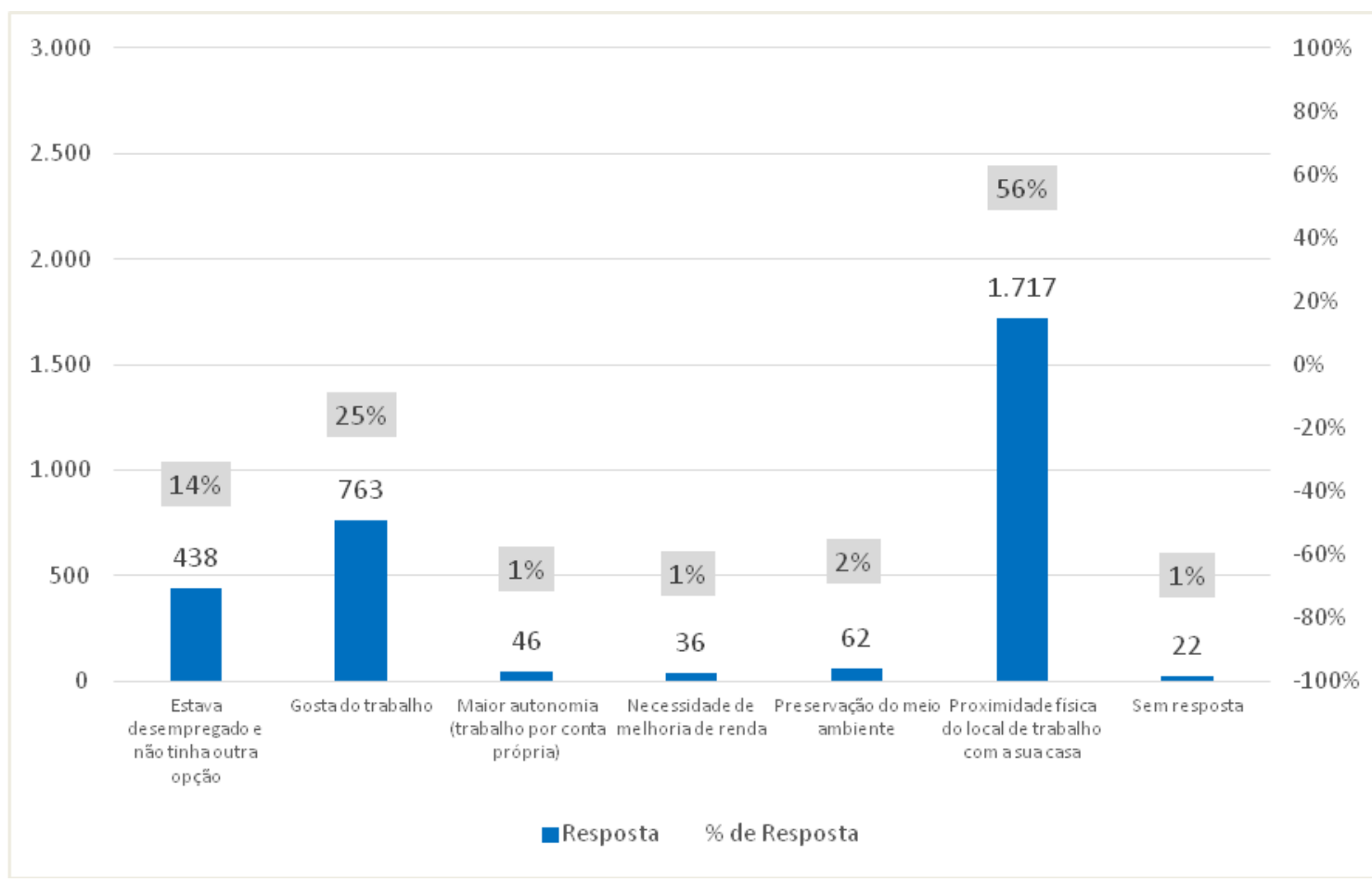

Fonte: Questionários aplicados pelo pesquisador no estudo realizado pela FGV e pelo Pangea e atualizados por meio do software CATAsig. Gráfico elaborado pelo autor, 2018.

Os dados demonstrados no Gráfico 5 revelam os motivos pelos quais os sujeitos entrevistados trabalham com a catação. A importância dada à proximidade física do local de trabalho com a residência corresponde a 56\% (1.717) dos entrevistados, sendo este o motivo mais significativo para que tal atividade profissional seja exercida. Em segundo lugar, está o gosto pelo trabalho, rendendo 25\% (763) de adeptos ao trabalho em questão. Em terceiro lugar, está a necessidade financeira e a ausência de outra opção geradora de renda, com 14\% (438). Esses 14\% veem na catação a única alternativa financeira viável.

A partir desses dados, é possível evidenciar o que Gonçalves (2006), Dagnino e Dagnino (2010) e Costa e Chaves (2012) já afirmavam sobre a importância e protagonismo de um dos atores que compõem e instituem a rede de reciclagem: os catadores. É preciso, neste momento, reafirmar a condição de marginalidade. Também vale lembrar o que aponta Santos (2008), sobre o circuito inferior em que se encontram esses sujeitos e, diante disso, sobre as 
CRUZ, U. R. X. C.

O perfil dos sujeitos sociais que compõem as redes de reciclagem do estado do Rio de Janeiro

poucas políticas públicas que são voltadas a eles, especialmente quando se trata de sua efetividade. Muito embora o estado do Rio de Janeiro e a rede em questão sejam um caso específico, pode-se encontrar uma realidade parecida nas mais diversas localidades do país, como explicitam os estudos de Medina (2007).

Ao compreender o espaço geográfico como as redes, os atores e o funcionamento das relações sociais como um todo, é inevitável não voltar o olhar para aqueles sujeitos que, de certo modo, se instituem como resistência a um poder heterônomo (FOUCAULT, 1995). Tais sujeitos, no contexto analisado, são alcunhados de catadores de materiais recicláveis. Estes vivenciam suas realidades nas entranhas dos espaços urbanos das cidades brasileiras e se veem inseridos em situação de abandono do Estado, com pouco acesso aos serviços públicos e às políticas públicas.

\section{Figura 1 - Espacialização dos locais de residência dos catadores de materiais recicláveis da RRERJ em 2017.}

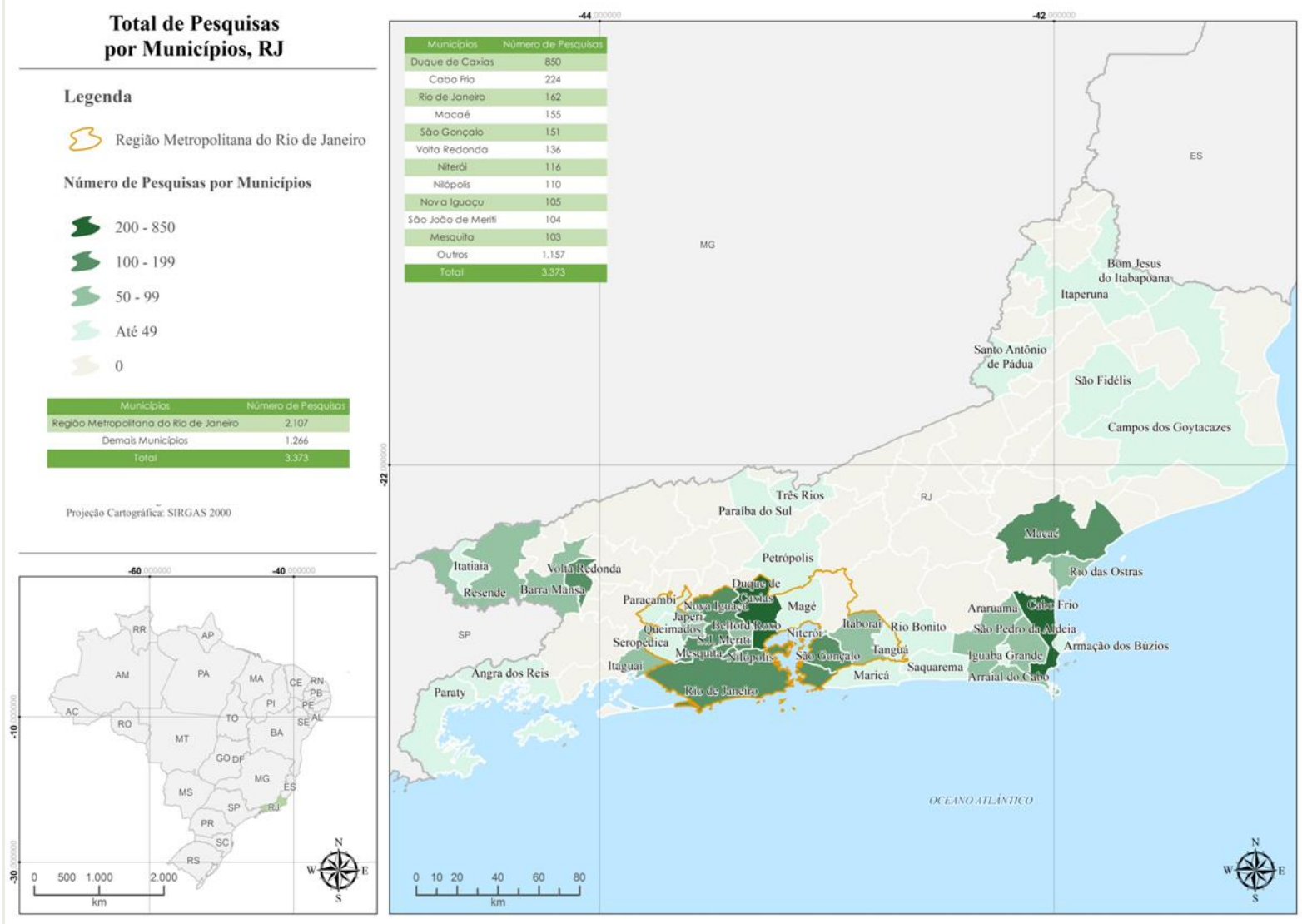

Fonte: Questionários aplicados pelo pesquisador no estudo realizado pela FGV / Pangea e atualizados por meio do software CATAsig. Imagem elaborada pelo autor, 2018. 
CRUZ, U. R. X. C.

O perfil dos sujeitos sociais que compõem as redes de reciclagem do estado do Rio de Janeiro

A relação espacial dos sujeitos entre centros de coleta e moradia é intrínseca. Os catadores de materiais recicláveis se estabelecem em localidades urbanas onde seus deslocamentos não dependam de despesas financeiras ou físicas, como gastos e tempo de deslocamento. Como já foi demonstrado em dados anteriores, a proximidade entre o local de trabalho e a residência é o fator de maior relevância para os que exercem a catação.

Mais uma vez, é possível perceber que o município de Duque de Caxias concentra o maior número de residências de catadores, com um total de $850^{6}$. Percebe-se também que não há catadores de materiais recicláveis em áreas rurais, visto que, como já sublinhado, a prática de catação de resíduos sólidos está ligada diretamente à industrialização, ao consumo de massa e ao espaço urbano.

Voltando a Silva (2017), é importante destacar sua posição acerca da precarização de trabalho entre os catadores de materiais recicláveis. O catador de lixo, conforme o autor, embora não tenha controle total sobre sua força de trabalho - o que se relaciona ao valor de mercado que a ela é atribuído —, é um importante ator na intensificação do fluxo do circuito superior da indústria da reciclagem.

A exploração da força de trabalho, relacionada à catação de lixo, não é definida pela qualidade, mas pela quantidade de material reciclável. Essa "objetificação" do trabalho, impressa pelas relações desiguais que compõem os circuitos inferior e superior da indústria da reciclagem, significa uma "não racionalidade" do catador, conferindo-lhe o imaginário de que ele não é um componente importante da rede de reciclagem, possibilitando assim sua marginalização, facilitando sua exploração e, por sua vez, a maximização do lucro para o circuito superior.

A confluência da discussão levantada por Silva (2017) e o presente trabalho ocorre no debate acerca de uma Geografia que inclui o olhar do sujeito pesquisado mediante o significado que o trabalhador atribui a sua prática laboral. Os apontamentos do autor são reforçados pelo argumento de que, apesar de uma subjetividade presente na realidade dos catadores que tange uma não racionalidade sobre sua força de trabalho e sua importância, as cooperativas colaboram para o empoderamento e uma alteração dessa lógica, a partir do

\footnotetext{
${ }^{6}$ Os dados aferidos na capital do Rio de Janeiro correspondem a dados coletados pelo sistema CATAsig durante as Olimpíadas e a Copa do Mundo, que foram eventos nos quais se pôde catalogar os catadores, mais precisamente os do Rio de Janeiro. Considera-se que esse mapa representa a real localidade em que o catador reside. Por isso, foi possível espacializar 289 catadores do município do Rio de Janeiro. Outrora, este dado pode não corresponder à realidade do município carioca. Porém, se for possível espacializar um quantitativo maior de catadores, eles estarão nas áreas periféricas.
}

Revista Cerrados, Montes Claros/MG, v. 18, n. 02, p. 123-151, jul./dez.-2020. 
CRUZ, U. R. X. C.

O perfil dos sujeitos sociais que compõem as redes de reciclagem do estado do Rio de Janeiro

envolvimento desses profissionais. A compreensão desses sujeitos sobre o trabalho da catação de material reciclável está traduzida em trechos apresentados por Silva (2017) a respeito de entrevistas que elevam a importância do meio ambiente na relação com a coleta seletiva do lixo (despoluição e diminuição de resíduos sólidos urbanos).

A constatação de que os catadores cooperados assumem uma visão de importância sobre seu ofício e uma mudança na significação que conferem a suas relações de trabalho caminha para a lógica de que os trabalhadores avulsos (não cooperados) sofrem uma intensificação da precarização de seus trabalhos. Assim, como demonstra Silva (2017), a função das cooperativas é também resgatar esses trabalhadores, pois tal política estabelece uma alteração territorial dos sujeitos, em um movimento da margem para o centro das relações de trabalho, por meio do empoderamento.

\section{CONSIDERAÇÕES FINAIS}

A Geografia, de forma geral, é uma ciência que pretende compreender os espaços geográficos. Contudo, seu viés social busca desvelar a relação dos indivíduos com esses espaços e todas as suas nuances, estabelecendo as multiplicidades de construções possíveis estabelecidas por essa relação.

Neste trabalho, foi possível compreender o espaço como construto social, ou seja, como fruto das relações entre os indivíduos que o ocupam, em um processo de constante construção de identidades. O espaço depende das relações sociais, assim como as relações sociais necessitam do espaço, sendo ambos interdependentes.

Assim, o objetivo deste trabalho foi refletir sobre o espaço e os sujeitos sociais relacionados à RRERJ. Para tanto, levou-se em conta que essa atividade exploratória e marginalizada é uma demanda particular do modo de produção capitalista que, por si só, gera uma grande quantidade de resíduos sólidos.

Resumidamente, este artigo se debruçou sobre as relações de poder que existem nas atividades de reciclagem e catação, observando o espaço e a construção da identidade dos sujeitos que compõem a RRERJ e traçando um perfil mais detalhado quantitativamente para eles.

Conclui-se, a partir dos dados quantitativos que corroboram com o que foi discutido neste trabalho, que os trabalhadores da atividade da reciclagem continuam ocupando 
CRUZ, U. R. X. C.

O perfil dos sujeitos sociais que compõem as redes de reciclagem do estado do Rio de Janeiro

uma posição de marginalização na sociedade, com poucas chances de ascensão devido a diversos fatores como: a baixa remuneração, que, no Rio de Janeiro, gira em torno de R\$ 651,00; a baixa escolarização, sendo que a maioria não concluiu o ensino básico; idades avançadas, já que grande parte da população de catadores é idosa; e a vulnerabilidade social, posto que há idosos que não possuem benefício previdenciário.

Por fim, cabe dizer este artigo procurou refletir sobre a importância de analisar as relações de trabalho e a exploração dos trabalhadores da coleta seletiva, colaborando, assim, para um entendimento melhor da organização desigual do espaço, já que, neste, é mantida uma lógica de exclusão, a partir das relações de trabalho e da posição social na qual os trabalhadores se inserem.

Certamente, esta revisão não pretende ser a única a tratar dessa temática. Pelo contrário, representa um esforço acerca de um tema que ainda é emergente na Geografia, podendo contribuir para uma compreensão das relações sociais e de trabalho no Brasil. Além disso, é importante colocar em evidência, por meio de estudos acadêmicos, a necessidade de olhar para os indivíduos excluídos e invisíveis da sociedade brasileira, desvelando e compreendendo todo o sistema que causa essas opressões e lutando para que um dia existam relações de trabalho mais equilibradas e benéficas para todos.

\section{AGRADECIMENTOS}

À Fundação de Amparo à Pesquisa do Estado de Minas Gerais - FAPEMIG pela concessão de bolsa de estudos.

\section{REFERÊNCIAS}

BAUMAN, Z. Identidade: entrevista a Benedetto Vecchi. Rio de Janeiro: Zahar, 2005. 110 p.

BOSI, A. P. A organização capitalista do trabalho "informal": o caso dos catadores de recicláveis. Revista Brasileira de Ciências Sociais, [S./l.], São Paulo, v. 23, n. 67, p. 101116, 2008.

BURGOS, R. Periferias Urbanas da Metrópole de São Paulo: territórios da base da indústria da reciclagem urbana periférica. 2008. 357 f. Tese (Doutorado em Geografia) Universidade de São Paulo, São Paulo, 2008.

CORREAA, R. L. Espaço, um conceito-chave da Geografia. In: CASTRO, I. E.; GOMES, P. C. C.; CORREA, R. L. (orgs.). Geografia: conceitos e temas. 2. ed. Rio de Janeiro: Bertrand Brasil, 2000, p. 15-48. 
CRUZ, U. R. X. C.

O perfil dos sujeitos sociais que compõem as redes de reciclagem do estado do Rio de Janeiro

COSTA, W. B.; CHAVES, M. R. Informalidade e precarização do trabalho de catação de materiais recicláveis no Brasil: pontos para debate. In: JORNADA DO TRABALHO, 13, 2012, Presidente Prudente. Anais... Presidente Prudente: CEGet, 2012. Disponível em: <http://www.proceedings.scielo.br/pdf/jtrab/n1/48.pdf>. Acesso em: 26 jul. 2020.

DAGNINO, R. S.; DAGNINO, R. P. Políticas para inclusão social dos catadores de materiais recicláveis. Pegada, Presidente Prudente, p. 65-93, jul. 2010. Disponível em:

$<$ http://professor.ufrgs.br/dagnino/files/dagnino_dagnino_2010_politicas_inclusao_catadores. pdf >. Acesso em: 26 jul. 2020.

DAMÁSIO, J. (coord.). Diagnóstico Econômico dos Catadores de Materiais Recicláveis da Região Metropolitana do Rio de Janeiro. [S. 1.]: UFBA; Centro de Estudos Socioambientais Pangea; Fundação Banco do Brasil; Petrobrás, 2018. No prelo.

FOUCAULT, M. Sujeito e poder. In: DREYFUS, H.; RABINOW, P. Michel Foucault, uma trajetória filosófica: para além do estruturalismo e da hermenêutica. Rio de Janeiro: Universitária, 1995, p. 231-250.

GOLDENBERG, M. A Arte de Pesquisar: como fazer pesquisa qualitativa em Ciências Sociais. 8. ed. Rio de Janeiro: Record, 2004. 110 p.

GONÇALVES, M. A. O Trabalho no Lixo. 2006. 310 f. Tese (Doutorado em Geografia) Universidade Estadual Paulista "Júlio de Mesquita Filho", Presidente Prudente, 2006.

HALL, S. A Identidade Cultural na Pós-Modernidade. 11. ed. Rio de Janeiro: DP\&A, 2011. 102 p.

HARVEY, D. O Enigma do Capital e as Crises do Capitalismo. São Paulo: Boitempo, 2011. $240 \mathrm{p}$.

INSTITUTO BRASILEIRO DE GEOGRAFIA E ESTATÍSTICA. Censo Demográfico de 2010: características gerais da população, religião e pessoas com deficiência. Rio de Janeiro: IBGE, 2012. Disponível em:

<http://biblioteca.ibge.gov.br/visualizacao/periodicos/94/cd_2010_religiao_deficiencia.pdf > Acesso em: 26 jul. 2020.

INSTITUTO BRASILEIRO DE GEOGRAFIA E ESTATÍSTICA. População chega a 205,5 milhões, com menos brancos e mais pardos e pretos. Agência IBGE, Rio de Janeiro, 24 nov. 2017. Disponível em: <http://agenciadenoticias.ibge.gov.br/agencia-noticias/2012-agenciade-noticias/noticias/18282-populacao-chega-a-205-5-milhoes-com-menos-brancos-e-maispardos-e-pretos>. Acesso em: 26 jul. 2020.

INSTITUTO DE PESQUISA ECONÔMICA APLICADA. Situação Social das Catadoras e dos Catadores de Material Reciclável e Reutilizável: região Sudeste. Brasília: IPEA, 2013. Disponível em:

<http://www.ipea.gov.br/portal/images/stories/PDFs/situacao_social/130910_relatorio_situac aosocial_mat_reciclavel_regiaosudeste.pdf>. Acesso em: 26 jul. 2020. 
CRUZ, U. R. X. C.

O perfil dos sujeitos sociais que compõem as redes de reciclagem do estado do Rio de Janeiro

LACOSTE, Y. A pesquisa e o trabalho de campo: um problema político para os pesquisadores, estudantes e cidadãos. Boletim Paulista de Geografia, São Paulo, v. 84, p. 77-92, 2006.

LUSSARI, W. R. Grupo de Apoiadores e Cooperlix em Presidente Prudente/SP, Brasil: modelo e evolução de suas relações durante quinze anos. 2016. 276 f. Tese (Doutorado em Geografia) - Universidade Estadual Paulista “Júlio de Mesquita Filho", Presidente Prudente, 2016.

MASSEY, D. B. Pelo Espaço: uma nova política da espacialidade. Rio de Janeiro: Bertrand Brasil, 2008. 312 p.

MEDINA, M. The World's Scavenger: salvage for sustainable consumption and production. Lanham: AltaMira Press, 2007. 320 p.

MINAYO, M. C. S. O desafio da pesquisa social. In: MINAYO, M. C. S. (org.); GOMES, S. F. D. R. Pesquisa Social: teoria, método e criatividade. 26. ed. Petrópolis: Vozes, 2017, p. 930 .

MINISTÉRIO DO TRABALHO E EMPREGO. Classificação Brasileira de Ocupações. 3. ed. Brasília: MTE; SPPE, 2010, v. 1. Disponível em:

<http://wp.ufpel.edu.br/observatoriosocial/files/2014/09/CBO-Livro-1.pdf>. Acesso em: 26 jul. 2020.

MOVIMENTO NACIONAL DOS CATADORES DE MATERIAIS RECICLÁVEIS.

Quantos catadores existem em atividade no Brasil? MNCR, São Paulo, 2019. Disponível em: $<$ http://mncr.org.br/sobre-o-mncr/duvidas-frequentes/quantos-catadores-existem-ematividade-no-brasil>. Acesso em: 26 jul. 2020.

POLLACK, M. Memória e identidade social. Estudos Históricos, Rio de Janeiro, v. 5, n. 10, p. 200-212, 1992.

PORTO-GONÇALVES, C. W. A Globalização da Natureza e a Natureza da Globalização. Rio de Janeiro: Civilização Brasileira, 2006. 462 p.

RAFFESTIN, C. Por uma Geografia do Poder. São Paulo: Ática, 1993. 270 p.

RAMIRES, J. C. L.; PESSOA, V. L. S. Pesquisas qualitativas: referências para pesquisa em Geografia. In: MARAFON, G. J.; RAMIRES, J. C. L; RIBEIRO, M. A.; PESSOA, V. L. S. (orgs.). Pesquisa Qualitativa em Geografia: reflexões teórico-conceituais e aplicadas. Rio de Janeiro: UERJ, 2013, p. 23-35.

ROSADO, R. M. Na Esteira do Galpão: catando leituras no território cotidiano da reciclagem do lixo de Porto Alegre/RS. 2009. 333 f. Tese. (Doutorado em Geografia) Universidade Federal do Rio Grande do Sul, Porto Alegre, 2009. 
CRUZ, U. R. X. C.

O perfil dos sujeitos sociais que compõem as redes de reciclagem do estado do Rio de Janeiro

SANTOS, B. S. A construção multicultural da igualdade e da diferença. Oficina do CES, Coimbra, n. 135, jan. 1999. 61 p. Disponível em:

<http://ces.uc.pt/publicacoes/oficina/ficheiros/135.pdf>. Acesso em: 26 jul. 2020.

SANTOS, M. O Espaço Dividido: os dois circuitos da economia urbana dos países subdesenvolvidos. 2. ed. São Paulo: USP, 2008. 431 p.

SILVA, M. C. P. O trabalho dos catadores de materiais recicláveis de Uberaba/MG e a relação com os dois circuitos econômicos da reciclagem. Pegada, Presidente Prudente, v. 18, n. 3, p. 202-233, 2017. Disponível em: <http://revista.fct.unesp.br/index.php/pegada/article/view/5257/4178>. Acesso em: 26 jul. 2020.

SOUZA, M. L. Os Conceitos Fundamentais da Pesquisa Sócio-Espacial. Rio de Janeiro: Bertrand Brasil, 2013. 320 p.

\section{Autor}

Uilmer Rodrigues Xavier da Cruz - É Graduado em Geografia - Ênfase em Sistemas de Informações Geográficas pela Pontifícia Universidade Católica de Minas Gerais (PUC-MG); Mestre em Geografia pela Universidade do Estado do Rio de Janeiro (UERJ). Atualmente é Doutorando em Geografia pela Universidade Federal de Minas Gerais (UFMG).

Artigo recebido em: 11 de maio de 2020.

Artigo aceito em: 14 de agosto de 2020.

Artigo publicado em: 19 de agosto de 2020. 